\title{
Glycan-binding specificities of Streptococcus mutans and Streptococcus sobrinus lectin-like adhesins
}

\author{
Viviane Schüler • Adrian Lussi • Andreas Kage • \\ Rainer Seemann
}

Received: 6 December 2010 / Accepted: 13 May 2011 /Published online: 17 June 2011

(C) Springer-Verlag 2011

\begin{abstract}
Since the adhesion of bacteria to the tooth surface is a prerequisite for dental plaque and subsequent caries development, a promising caries preventive strategy could be to block the lectin-glycan-mediated adherence of cariogenic bacteria. The aim of the study was to evaluate potential differences in glycan-binding specificities of two Streptococcus mutans strains (DSM 20523 and DSM 6178) and Streptococcus sobrinus (DSM 20381). A competitive enzyme-linked lectin-binding assay was used to identify the binding specificities of isolated bacterial surface lectins. Blotting of the microbial proteins on neoglycoprotein-coated PVP membranes enabled a qualitative protein analysis of all specific bacterial lectins. Different glycan-binding sites could be identified for the $S$. mutans strains in comparison to $S$. sobrinus. An earlier reported glycan-binding specificity for terminal galactose residues could be confirmed for the $S$. mutans strains. For the S. sobrinus strain, more than one glycan-binding specificity could be found (oligomannose and terminal sialyl residues). Each of the tested strains showed more than one surface lectin responsible for the specific lectin-binding with varying molecular weight
\end{abstract}

V. Schüler $\cdot$ R. Seemann

Department of Operative and Preventive Dentistry, Charité, Humboldt University,

Berlin, Germany

\section{A. Lussi $\cdot$ R. Seemann $(\bowtie)$}

Department of Preventive, Restorative and Pediatric Dentistry, University of Bern,

Freiburgstrasse 7 ,

3010 Bern, Switzerland

e-mail: rainer.seemann@zmk.unibe.ch

A. Kage

Technical University Berlin,

Berlin, Germany
(S. mutans, 90/155 kDa and S. sobrinus, 35/45 kDa). The established experimental setup could be used as future standard procedure for the identification of bacterial lectinderived binding specificities. The findings from this study might serve as basis for the design of an individual 'glycan cocktail' for the competitive inhibition of lectin-mediated adhesion of mutans streptococci to oral surfaces.

Keywords Dental caries $\cdot$ Streptococcus mutans . Streptococcus sobrinus $\cdot$ Lectin-like adhesins .

Glycan pattern

\section{Introduction}

Several microorganisms have been identified from carious lesions of which Streptococcus mutans and Streptococcus sobrinus are the most prevalent pathogenic species in humans involved in the initiation and development of dental caries [1-4]. The high cariogenic potential especially of $S$. mutans derives from the ability to produce high amounts of organic acid and extracellular glycans in the presence of low molecular sugars $[3,5,6]$.

Consequently, established preventive strategies such as dietary control, topical or systemic use of fluorides and fissure sealants have led to a significant caries decline [7, 8]. However, caries is still causing high costs in health systems. Due to the current stagnation within caries prevention [9], continuing development of innovative preventive strategies and techniques seems to be indispensable to minimize further expansion of this widespread disease.

Since the adhesion of bacteria to the tooth surface represents the initial step in the pathogenesis of dental plaque formation and subsequent caries development [10], an anti-adhesive therapy gains significant importance by a 
possible prevention of specific lectin-mediated adherence mechanisms [11-13]. Studies concentrating on salivary glycans have indicated that specific soluble glycoconjugates in sufficient concentrations have the ability to competitively inhibit the adherence of bacterial lectins of caries-inducing microorganisms to immobilized glycoconjugates on oral surfaces $[14,15]$. Thus, the aim of this study was to evaluate potential differences in glycan-binding specificities of two $S$. mutans strains and S. sobrinus.

\section{Materials and methods}

Both $S$. mutans strains (DSM 20523 and DSM 6178) and $S$. sobrinus (DSM 20381) were obtained in lyophilisated form by the DSMZ (Deutsche Sammlung von Mikroorganismen und Zellkulturen, Braunschweig, Germany). Individual colonies of each strain were cultivated in universal broth agar (CASO-Bouillon, heipha, D-Eppelheim) within 1 week. The resulting bacterial suspensions were each biotinylated (0.5 mg Sulfo-NHS-LC-Biotin per millilitre reaction volume, solved in $50 \mathrm{mM} \mathrm{Na}_{2} \mathrm{CO}_{3}$ buffer, $\mathrm{pH} 8.0$ ), lysed (five times, $50 \mathrm{ml}$ lysing buffer, $\mathrm{pH} 8.0,10 \mathrm{~min}, 5,000 \mathrm{rpm}$ ) and finally filtrated (PES filter $0.2 \mu \mathrm{m} / 10 \mathrm{kDa}$, Vivaflow 50 , Vivascience, Göttingen, Germany/10 kDa palfiltrons, Amicon ${ }^{\circledR}$ Ultra-4, Millipore, Billerica, MA, USA) in order to obtain bacterial homogenates $>10 \mathrm{kDa},<0.2 \mu \mathrm{l}$, including their biotinylated surface membrane proteins of lectin type. The $\mathrm{BCA}^{\mathrm{TM}}$ Protein Assay-Kit (Pierce, Rockford, IL, USA) was used to adjust all bacterial homogenates to the same total protein concentration.
A competitive enzyme-linked lectin-binding inhibition assay was used to determine the binding specificity of bacterial surface lectin-like adhesins towards lectin-specific glycan patterns, as well as the potential binding inhibition by soluble complementary glycans in dependence on their concentration (Fig. 1). Based on the principle of the competitive lectin-binding inhibition assay described by Kage et al. [16], several microtitre plates were pre-coated with immobilized neoglycoproteins $(1: 1,000$, solved in $0.1 \mathrm{M} \mathrm{Na}_{2} \mathrm{CO}_{3}$ buffer, $\left.\mathrm{pH} 8.5,100 \mu \mathrm{l}\right)$, with corresponding binding specificities towards well-known lectins. The following purified plant and animal lectins with known specificity for different glycan patterns were used in this study: peanut agglutinin (PNA, specific for $\beta$-galacto1,3- $N$-acetyl-galactosamine, Sigma-Aldrich, Steinheim, Germany), Galanthus nivalis agglutinin (GNA, specific for terminal mannose residues, EY Laboratories Inc., San Mateo, CA, USA), Concanavalin A (ConA, specific for trimannosyl structures in high mannose type $N$-glycans, Sigma-Aldrich, Steinheim, Germany), Sambucus nigra agglutinin (SNA, specific for $\alpha$-2,6-sialyl residues, EY Laboratories Inc., San Mateo, CA, USA) and Anguilla anguilla agglutinin (AAA, specific for $\alpha-1,6$-fucose, EY Laboratories Inc., San Mateo, CA, USA) [17]. The following neoglycoproteins were used for pre-coating of the microtitre plates: BSA-galactose-1,3- $N$-acetyl-galactosamine (specific for PNA, Dextra Laboratories, Reading, UK), BSA$\alpha$-mannopyranoside (specific for GNA and ConA, SigmaAldrich, Steinheim, Germany), BSA-fucosylamide (specific for AAA, Sigma-Aldrich, Steinheim, Germany) and fetuin
Fig. 1 Scheme of the competitive lectin-binding inhibition assay used to determine the binding specificity of bacterial surface lectin-like adhesins towards lectin-specific glycan patterns as well as the potential binding inhibition by soluble complementary glycans in dependence on their concentration
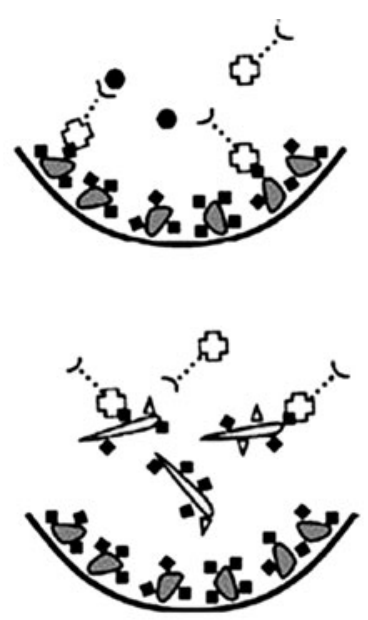

immobilized neoglycoproteins biotinylated bacterial lectins neutravidin-peroxidase soluble complementary glycans
Biotinylated bacterial lectins bind to the immobilized neoglycoprotejns depending on their glycan-binding specificity. The bound lectin can be quantified using the neutravidin-peroxidaxe detection system.

Soluble complementary glycans have the potential to inhibit these lectin-bindings to immobilized neoglycoproteins in dependence on their concentration. 
(specific for SNA, Sigma-Aldrich, Steinheim, Germany). Unbound neoglycoproteins were removed during washing (three times, $200 \mu \mathrm{l}, 50 \mathrm{mM}$ tris(hydroxymethyl)-aminomethane, $0.1 \%$ Tween $20, \mathrm{pH} 7.5$ ) after overnight incubation at $4^{\circ} \mathrm{C}$. Subsequently, double rows on each microtitre plate were incubated with $75 \mu 1$ of the specific standard lectin $(1 \mathrm{mg} / \mathrm{ml}, 1: 20,000$ in probing buffer: $50 \mathrm{mM}$ Tris- $\mathrm{HCl}$, $150 \mathrm{mM} \mathrm{NaCl}, 0.1 \mathrm{mM} \mathrm{MnCl} 2,0.5 \mathrm{mM} \mathrm{CaCl}_{2}, 2.0 \mathrm{mM}$ $\mathrm{MgCl}_{2}, 0.025 \mathrm{mM} \mathrm{ZnCl}$, $\mathrm{pH} 7.5$ ) and analogous all bacterial homogenates (approximately $730 \mu \mathrm{g} / \mathrm{ml}, 1: 1,500$ in probing buffer, $\mathrm{pH} 7.5$ ), each together with $25 \mu 1$ soluble complementary glycans (methyl-D-galactopyranoside (specific for PNA, Sigma-Aldrich, Steinheim, Germany), mannan (specific for GNA, Sigma-Aldrich, Steinheim, Germany), $\alpha$-L-(-)-fucose (specific for AAA, Sigma-Aldrich, Steinheim, Germany), methyl- $\alpha$-mannopyranoside (specific for ConA, Sigma-Aldrich, Steinheim, Germany) and $N$-acetyl-neuraminlactose (specific for SNA, Dextra Laboratories, Reading, UK) in different concentrations following a geometrically dilution (in probing buffer, $\mathrm{pH}$ 7.5). Additionally, each double row included a blank value to evaluate possible unspecific bindings between buffer and immobilized neoglycoproteins, as well as the maximal lectin binding without the addition of complementary soluble glycan. Finally, all plates were incubated shaking for $30 \mathrm{~min}$ at room temperature, then overnight at $4^{\circ} \mathrm{C}$. Washing (three times, $200 \mu \mathrm{l}$ ) allowed the elimination of all unbound or by soluble complementary glycans bound lectins. Only lectin molecules bound to the immobilized glycoproteins were detected by the neutravidin peroxidase detection system $(100 \mu \mathrm{l}, 1 \mathrm{mg} / \mathrm{ml}, 1: 20,000$ in probing buffer) during a $1-\mathrm{h}$ incubation at room temperature (followed by a washing procedure, four times, $200 \mu \mathrm{l}$ ). The colour change induced by tetramethylbenzidin substrate (1:100 solved in galatti buffer, stopped with $50 \mu \mathrm{l} 4 \mathrm{~N}$ $\mathrm{H}_{2} \mathrm{SO}_{4}$ ) allowed finally the colorimetrically determination in a spectral photometer (450 to $492 \mathrm{~nm}$, Ultra 384, Tecan, Crailsheim, Germany). Non-carbohydrate-lectin-specific bindings between the lectins and the immobilized neoglycoproteins could be further measured by incubation with the lectins in the presence of deglycosylated, immobilized neoglycoproteins in the same experimental setup. In the attempt to identify only the bacterial surface proteins responsible for the lectin-mediated binding specificities, deglycosylated glycoconjugates were obtained by using oxidative separation of their terminal glycan structures.

Sodium dodecyl sulphate-polyacrylamide gel electrophoresis (SDS-PAGE) of the bacterial homogenates was performed with a $10 \%$ polyacrylamide gel (CleanGel, $52 \mathrm{~S}$, ETC, Kirchtellinsfurt, Germany) under reducing conditions (10 $\mu 12.5 \mathrm{M}$ DTT to $1 \mathrm{ml}$ buffer). The gels were calibrated with the following molecular weight standards: Precision Plus (10-250 kDa, Bio-Rad, Hercules, CA, USA), pre-stained Multi Mark (4-250 kDa, Invitrogen, Karlsruhe, Germany) and biotinylated SDS Molecular Weight Standard (6.5180 kDa, Sigma-Aldrich, Steinheim, Germany). Silver staining (GE Healthcare Biosciences, Freiburg, Germany) enabled to uncover all proteins of each bacterial homogenate separated by their molecular weight. Based on the Western Blot technique, a contact blot was newly developed to transfer the SDS-PAGE separated proteins by diffusion to glycanspecific polyvinyl difluoride (PVP) membranes (Fig. 2). The glycan-specific PVP membranes were obtained by incubation (overnight at $4^{\circ} \mathrm{C}$ after activation with $100 \%$ methanol for $10 \mathrm{~min}$ ) with the same complementary glycoconjugates used in the lectin assay described above. Both the PVP membranes and the SDS gels were equilibrated in transfer buffer (12 mM tris(hydroxymethyl)-aminomethane, $96 \mathrm{mM}$ glycine, $20 \%$ methanol) for $15 \mathrm{~min}$. The PVP membranes were then blotted under the weight of $5 \mathrm{~kg}$ in a blot sandwich (lower glass plate-SDS gel-PVP-membrane-5× filter paper-upper glass plate) for $1.5 \mathrm{~h}$ with the by electrophoresis-separated microbial proteins. This technique enabled a qualitative protein analysis of only the bacterial lectins responsible for the specific binding to a specific neoglycoprotein. After blocking remaining binding sites (60 $\mathrm{min}$ at room temperature, $20 \mathrm{mM}$ tris(hydroxymethyl)aminomethane, $137 \mathrm{mM} \mathrm{NaCl}, 2.0 \%$ Tween 20, pH 7.6) and incubation with the neutravidin peroxidase detection system (60 $\mathrm{min}, 1 \mathrm{mg} / \mathrm{ml}, 1: 10,000$ in probing buffer) followed by

Bacterial proteins seperated by their molecular weight after SDS-gel electrophoresis
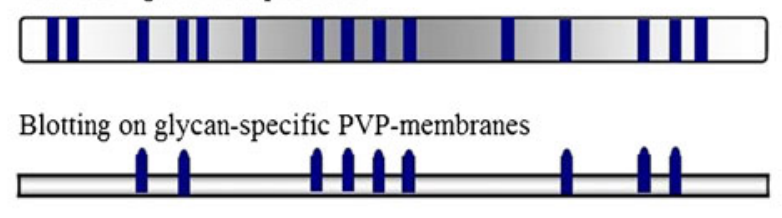

Blocking buffer
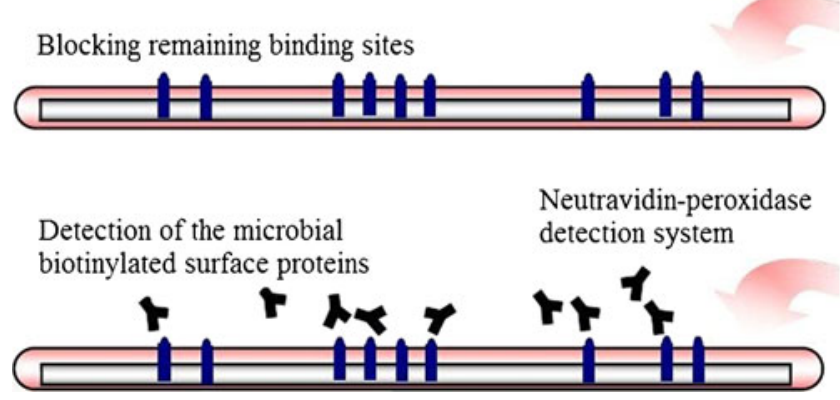

Fig. 2 Scheme of the contact blot. SDS-PAGE-separated bacterial proteins were blotted on glycan-specific polyvinyl difluoride (PVP)membranes enabling a qualitative protein analysis of only the bacterial lectins responsible for a specific glycan binding. The following glycans were used: methyl-D-galactopyranoside (specific for PNA), mannan (specific for GNA), $\alpha$-L-(-)-fucose (specific for AAA), methyl- $\alpha$-pyranoside (specific for ConA) and NAC-neuraminlactose (specific for SNA). Using the neutravidin peroxidase detection system, only the specific microbial biotinylated surface proteins could be visualized by Enhanced Chemo-luminescence 
several washing steps $(1 \times 15$ and $3 \times 5 \mathrm{~min}$, shaking in washing buffer), the visualization of these specific proteins was achieved by Enhanced Chemo-luminescence (solution 1 +2 mixed 1:1, $0.125 \mathrm{ml} / \mathrm{cm}^{2}$, Pharmacia Biotech, Piscataway, NJ, USA) onto a sensitive film (exposure time from 0.25 to $5 \mathrm{~min}$, High Performance Chemiluminescence Film, Amersham Biosciences). The exclusion of all noncarbohydrate-lectin-based binding mechanisms was again obtained by applying deglycosylated glycan patterns to the PVP membranes in the same experimental setup using the purified plant and animal lectins (PNA, GNA, ConA, SNA and AAA) with the corresponding specificities as control. Accordingly, to the competitive enzyme-linked lectinbinding inhibition assay, all lectin-like adhesins with binding specificities to the deglycosylated PVP membranes were excluded from further consideration.

\section{Results}

All bacterial lectins showed a reproducible individual binding behaviour with regard to the glycans tested. Figure 3 illustrates the competitive binding inhibition by different soluble complementary glycans towards the tested bacterial strains $S$. mutans DSM 20523 and DSM 6178, as well as S. sobrinus DSM 20381 in comparison to the corresponding standard lectin with known specificity for the tested glycans. Each purified standard lectin (PNA (peanut agglutinin), GNA ( $G$. nivalis agglutinin), ConA (Concanavalin A), SNA (S. nigra agglutinin) and AAA (A. anguilla agglutinin)) presents the typical graph of a sigmoidal curve with a clear decrease of the lectin binding (percent) to a rising concentration of the soluble complementary glycan. By using deglycosylated neoglycoproteins, all identified non-lectin bindings between the bacterial homogenates and the immobilized neoglycoproteins could be excluded from further regards.

Earlier reported glycan-binding specificity for terminal galactose residues could be confirmed for the two $S$. mutans strains tested. Although minimal concentrations of the soluble complementary glycan seem to be enough to inhibit the lectin binding, differences appear in the degree of the $50 \%$ binding inhibition. While approximately $2.5 \mathrm{mM}$ of methyl-D-galactopyranoside was sufficient to reduce $S$. mutans DSM 6178, approximately $5.0 \mathrm{mM}$ was necessary to evoke the $50 \%$ binding inhibition for $S$. mutans DSM 20523 (Fig. 3a). Additionally, the finding of a significant mannose-binding specificity in the form of an oligomannose of the $S$. sobrinus strain could be made. Figure $3 \mathrm{~b}$ demonstrates that only $0.1 \mu \mathrm{g} / \mathrm{ml}$ appears to be enough to cause the $50 \%$ binding inhibition of the bacterial lectin binding. Contrarily, branched mannose structures without terminal mannose residues had no influence on the binding specificity on none of the tested strains (Fig. 3c). Terminal sialyl residues were shown to inhibit $S$. sobrinus as well. A comparatively high amount of $\mathrm{N}$-acetyl-galactosamine $(10 \mathrm{mg} / \mathrm{ml}$ ) was needed for the $50 \%$ inhibition (Fig. 3d). The specificity for terminal fucose could be excluded for all tested mutans streptococci (Fig. 3e).

Blotting of the bacterial proteins separated by their molecular weight onto glycan-specific PVP membranes revealed more than one surface lectin responsible for the specific lectin binding for each of the tested strains (Table 1 and Fig. 4). S. mutans DSM 20523 and DSM 6178 showed PNA-specific surface lectins with varied molecular weights of 90 and $155 \mathrm{kDa}$. S. sobrinus DSM 20381 showed GNAspecific surface lectins of 35 and $45 \mathrm{kDa}$. Regarding the SNA specificity of $S$. sobrinus DMS 20381, no clear information can be given according to the molecular weight of the corresponding surface lectin because of only slight differences between the glycosylated and deglycosylated PVP membranes (Fig. 4). A molecular weight around 25 to $35 \mathrm{kDa}$ can be assumed; however, further verification is needed.

\section{Discussion}

Long-term survival of bacteria in the oral cavity requires that the microorganisms have the ability to adhere to a tissue surface or colonize a suitable niche in the complex biofilm. One of the many molecular mechanisms involved in initial adherence of bacteria to the acquired pellicle and subsequent development of mixed species oral biofilms is the specific lectin-carbohydrate interaction between the microorganisms and their host $[12,13]$.

Individual host defence factors of the saliva and crevicular fluid protect the human organism to a certain degree of accumulating or invading microorganisms. Besides the systemic immune system, available soluble glycoconjugates in saliva play an important role as a constitutional host defence factor in terms of a first line of defence [14]. While promoting the bacterial adhesion on the one hand, they can specifically prevent the binding of bacteria by competitively blocking their adhesion on the other hand $[12,18]$ depending on their concentration available.

Whereas Zehetbauer et al. could not detect any significant differences in the salivary protein profiles between children with early childhood caries and caries-free children [19], Seemann et al. found that salivary glycoconjugates of cariesresistant children from a representative sample showed a higher binding inhibition against the lectin PNA (specific for terminal galactosyl residues) compared to saliva of cariessusceptible children [15]. Studies concentrating on patients with periodontal disease revealed a lack of terminal $N$-acetylgalactosamine residues, specific for Vicia villosa agglutinin 

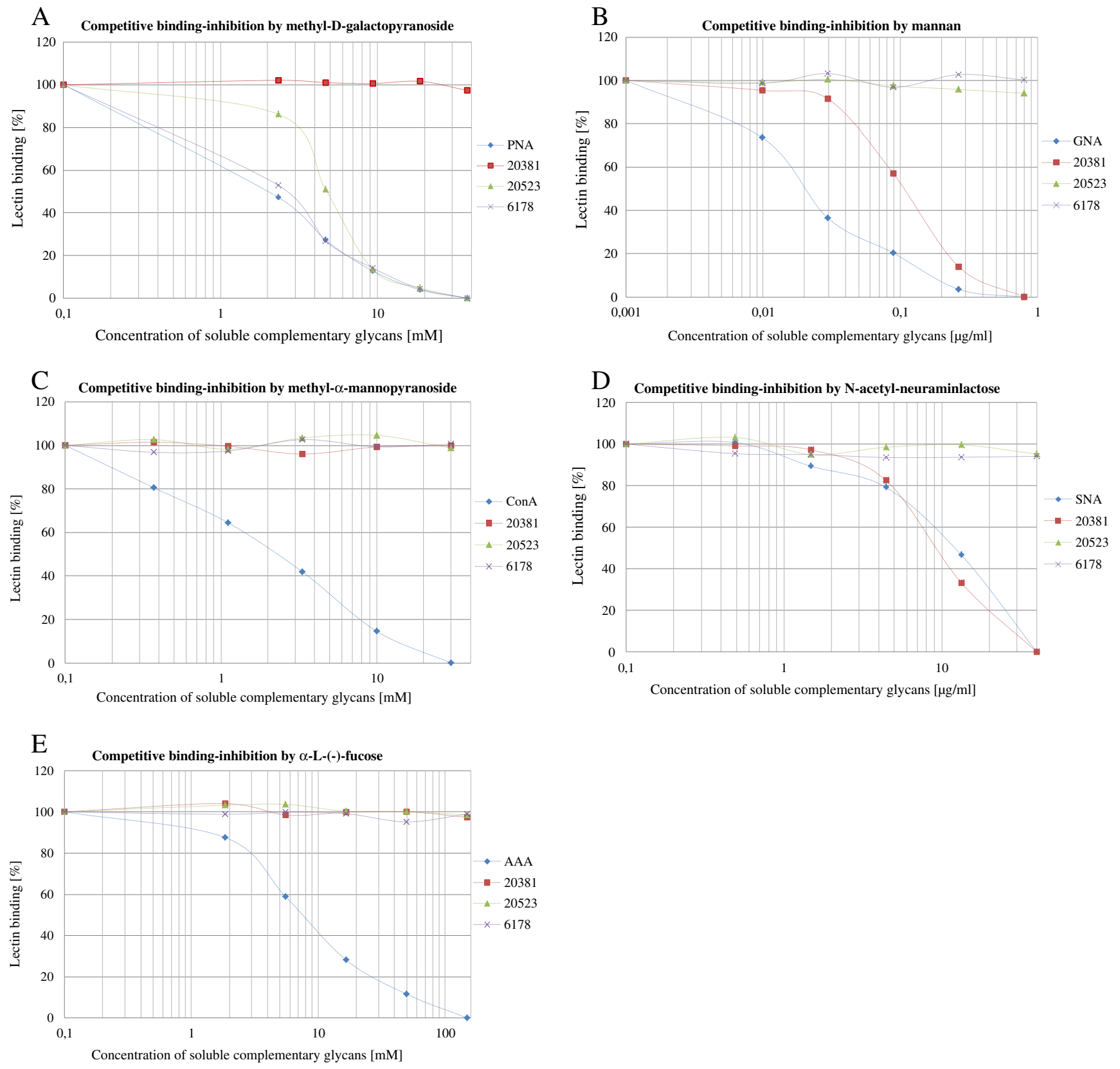

Fig. 3 Competitive binding inhibition of the bacterial homogenates from Streptococcus mutans (DSM 20523), S. mutans (DSM 6178) and Streptococcus sobrinus (DSM 20381) in the presence of soluble glycans with PNA-specific glycan patterns (a), GNA-specific glycan

[16]. Further research demonstrated a significant increase of specific salivary glycoconjugates during a progressive bacterial contamination in the oral cavity [20]. These data indicate that a reduced availability of distinct glycosylation patterns may act as an additional host-derived factor for an increased occurrence of specific microorganisms within a certain disease.

Anti-adhesion therapy aims the inhibition or complete blocking of lectin-mediated adhesion with the intention to reduce the initial adhesion of pathogenic microorganisms

patterns (b), ConA-specific glycan patterns (c), SNA-specific glycan patterns (d) and AAA-specific glycan patterns. (e) PNA peanut agglutinin, GNA Galanthus nivalis agglutinin, ConA Concanavalin A, SNA Sambucus nigra agglutinin, AAA Anguilla anguilla agglutinin

on host tissues without affecting their viability to prevent selective pressure and overgrowth of resistant bacteria. The infection of the urothelium by Escherichia coli for instance could be effectively inhibited after applying lectin-specific methyl- $\alpha$-D-mannopyranoside [21]. Consequently, this model can be applied to the colonization of oral pathogens such as cariogenic $S$. mutans and S. sobrinus in order to prevent initial adhesion as a first step in the multi-factorial caries aetiology. Although the lectin-mediated binding specificities of caries-inducing microorganisms are not very 
Table 1 Molecular weights of the specific bacterial surface lectins depending on their binding specificities

\begin{tabular}{llll}
\hline Binding specificities of the bacterial surface proteins (lectins) & DSM 20523 & DSM 6178 & DSM 20381 \\
\hline$\beta$-galacto-1,3- $N$-acetyl-galactosamine (PNA-specific) & $90 \mathrm{kDa}$ & $90 \mathrm{kDa}$ \\
& $155 \mathrm{kDa}$ & - & $35 \mathrm{kDa}$ \\
Terminal mannose residues (GNA-specific) & - & - & - \\
& - & - & - \\
Branched mannose residues (ConA-specific) & - & - & Further verification needed \\
$\alpha$-2,6-Sialyl residues (SNA-specific) & - & - \\
$\alpha$-1,6-Fucose (AAA-specific) & & \\
\hline
\end{tabular}

well characterized yet, studies revealed that a high molecular mass cranberry constituent was capable of reducing mutans streptococci level in saliva and effectively inhibiting in vitro adhesion to hydroxyapatite [22, 23]. Furthermore, studies in an artificial mouth model showed a caries-preventive effect of an experimental glycan solution prepared by hydrolysis of porcine gastric mucine on natural teeth [24]. Early adhesion experiments by Gibbons and Qureshi revealed that the adhesion of different S. mutans serotypes to saliva-coated hydroxyapatite could be inhibited by galactose and melibiose (6- $\alpha$-D-galactosyl-glucose) but not by lactose [25]. Further experiments by other investigators supported the assumption that galactose residues seem to have a significant meaning within the lectin-mediated adhesion of $S$. mutans [26-28]. In the present study, these findings could be confirmed for the two S. mutans strains (DSM 20523 and DSM 6178) tested in the present study.

Nevertheless, terminal galactose residues had no influence on the adherence of $S$. sobrinus DSM 20381, which supports early observations that $S$. mutans and $S$. sobrinus attach to different receptors in experimental pellicles [29]. Instead, $S$. sobrinus showed a significant mannose-binding specificity in

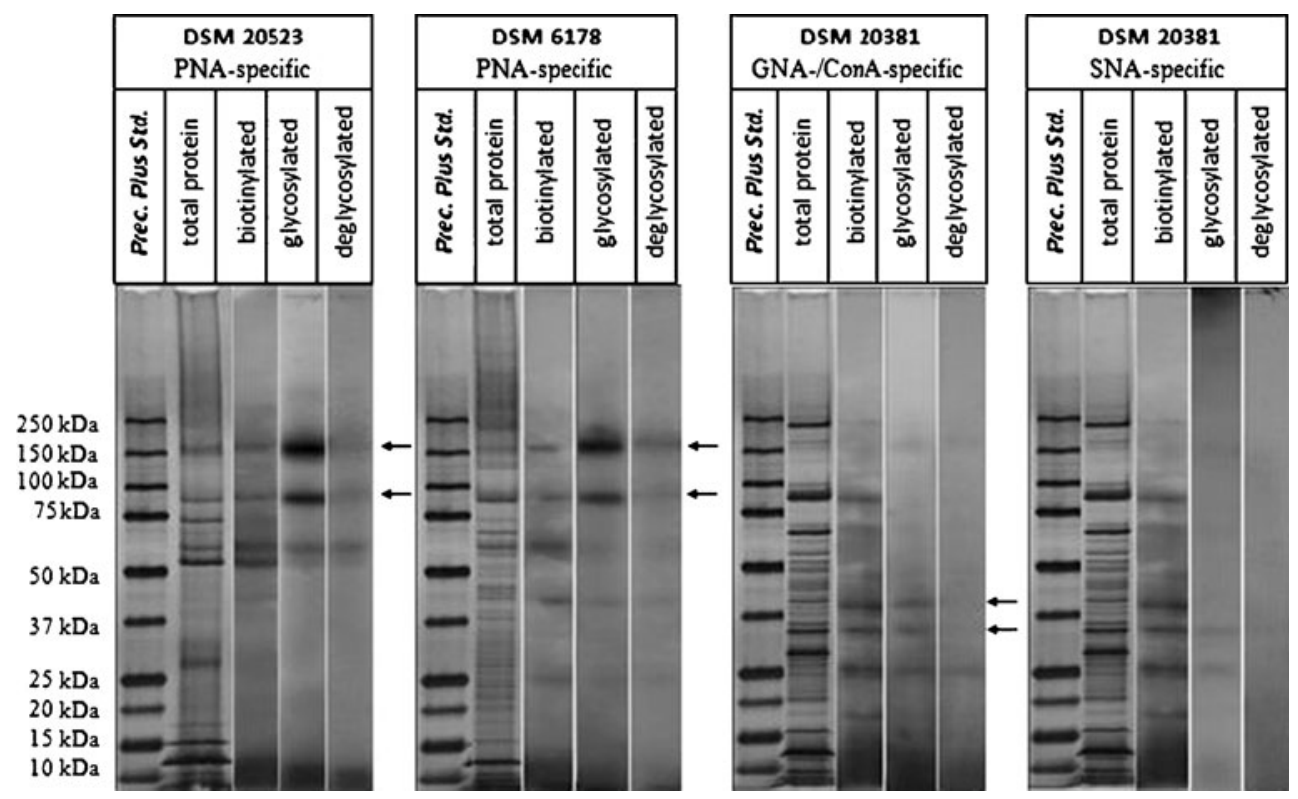

Fig. 4 Overview of the different binding specificities of Streptococcus mutans DSM 20523, S. mutans DSM 6178 and Streptococcus sobrinus DSM 20381 regarding the molecular weights of their specific bacterial surface lectins. For each tested strain, the proteins are displayed in four columns, always in comparison to the Precision Plus molecular weight standard (left column). While the total protein identifies all verifiable proteins within the bacterial homogenate of each strain (both from the surface and the bacterial inside), the biotinylated column shows only the proteins of the bacterial surface membrane with possible lectin specificity. Using glycosylated membranes, only the bacterial surface proteins responsible for a specific binding to a certain neoglycoprotein could be identified (PNA-specific binding of S. mutans DSM 20523 and S. mutans DSM 6178, as well as the GNA-/ConA-specific and SNA-specific binding of S. sobrinus DSM 20381 could be found). By using deglycosylated membranes, the bacterial surface proteins responsible for the lectin-mediated binding specificities could be identified. Only the proteins marked by the arrows bind on carbohydrate-lectin-mediated binding mechanisms (binding reduction because of the separation of the terminal glycan structures of the neoglycoproteins). For each specific lectinbinding of the tested strains, more than one surface lectin with varied molecular weight could be identified (PNA-specific 90/155 kDa of $S$. mutans DSM 20523 and S. mutans DSM 6178; GNA-/ConA-specific $35 / 45 \mathrm{kDa}$ of S. sobrinus DSM 20381) 
form of an oligomannose (GNA specific). Interestingly, a branched monomannose structure without terminal mannose residues (ConA specific) had no influence on the binding specificity on the tested strains. The present results identified another novel aspect of bacterial lectins: terminal sialyl residues were also shown to inhibit $S$. sobrinus.

The comparable less distinctive binding inhibition of $S$. sobrinus by sialyl residues may be explained by a glycosylation pattern, which is very similar but does not absolutely correspond to the lectin-binding specificity. Respectively, it can be assumed that there are further surface lectin-binding specifities available for S. mutans as well.

In all bacterial strains, we identified more than one surface lectin (Fig. 4) capable of the specific lectin binding with varied molecular weight (S. mutans, $90 / 155 \mathrm{kDa}$ and S. sobrinus, $35 / 45 \mathrm{kDa}$ ), which supports speculations that epitopes necessary for a specific adherence can be found on multiple proteins [30]. For SNA-specific binding of $S$. sobrinus, a molecular weight of around 25 to $35 \mathrm{kDa}$ can be speculated, but further investigation is needed (Fig. 4 and Table 1). Because of the heterogeneous binding behaviour of caries-relevant microorganisms, anti-adhesive agents should be adapted to the individual adhesion specificity. Further studies concentrating on the revelation of the bacterial surface lectin-binding specificities will elucidate the effectiveness of glycoconjugates as anti-adherence agents.

Regarding the established experimental concept and technique, this present in vitro study might be used as a future standard procedure for the identification of the individual binding specificity of predominant cariesinducing microorganisms.

\section{Conclusions}

In conclusion, these findings suggest that mutans streptococci possess surface lectins with heterogeneous glycan-binding sites in order to adhere to oral surfaces. Different glycanbinding sites could be identified for the $S$. mutans strains in comparison to $S$. sobrinus. For the $S$. sobrinus strain, more than one glycan-binding specificity could be detected. An earlier reported glycan-binding specificity for terminal galactose residues could be confirmed for the $S$. mutans strains.

Conflicts of interest The authors declare that they have no conflicts of interest.

\section{References}

1. Nurelhuda NM, Al-Haroni M, Trovik TA, Bakken V (2010) Caries experience and quantification of Streptococcus mutans and Streptococcus sobrinus in saliva of Sudanese schoolchildren. Caries Res 44:402-407
2. Choi EJ, Lee SH, Kim YJ (2009) Quantitative real-time polymerase chain reaction for Streptococcus mutans and Streptococcus sobrinus in dental plaque samples and its association with early childhood caries. Int J Paediatr Dent 19:141-147

3. Loesche WJ (1986) Role of Streptococcus mutans in human dental decay. Microbiol Rev 50:353-380

4. Fitzgerald RJ, Keyes PH (1960) Demonstration of the etiologic role of streptococci in experimental caries in the hamster. J Am Dental Assoc 61:9-19

5. Matsumura M, Izumi T, Matsumoto M, Tsuji M, Fujiwara T, Ooshima $\mathrm{T}$ (2003) The role of glucan-binding proteins in the cariogenicity of Streptococcus mutans. Microbiol Immunol 47:213-215

6. Koo H, Xiao J, Klein MI (2009) Extracellular polysaccharide matrix - an often forgotten virulence factor in oral biofilm research. Int J Oral Sci 1:229-234

7. Ericsson Y (1978) Progress in caries prevention. Caries Res 12 (Suppl):1-112

8. Micheelis W, Schiffner U (2006) Vierte Deutsche Mundgesundheitsstudie (DMS IV). Neue Ergebnisse zu oralen Erkrankungsprävalenzen, Risikogruppen und zum zahnärztlichen Versorgungsgrad in Deutschland 2005, vol. 31. Deutscher Zahnärzte Verlag

9. Marthaler TM (2004) Changes in dental caries 1953-2003. Caries Res 38:173-181

10. Gibbons RJ (1989) Bacterial adhesion to oral tissues: a model for infectious diseases. J Dental Res 68:750-760

11. Kelly CG, Younson JS (2000) Anti-adhesive strategies in the prevention of infectious disease at mucosal surfaces. Expert Opin Invest Drugs 9:1711-1721

12. Ofek I, Hasty DL, Sharon N (2003) Anti-adhesion therapy of bacterial diseases: prospects and problems. FEMS Immunol Med Microbiol 38:181-191

13. Sharon N (2006) Carbohydrates as future anti-adhesion drugs for infectious diseases. Biochim Biophys Acta 1760:527-537

14. Kage A, Fimmel S, Bernimoulin JP, Hagewald S, Nitschke I, Kage R, Kottgen E (1995) Oligosaccharides in mucosal host defense: model, method, and first data. Adv Exp Med Biol 371B:1177-1182

15. Seemann R, Zimmer S, Bizhang M, Kage A (2001) Differences in the salivary glycan pattern between children with high and low caries susceptibility. Caries Res 35:156-161

16. Kage A, Weitzel D, Köttgen E (1989) Novel competitive lectinbinding inhibition assay for quantitative characterization of glycoconjugates using different peroxidase labeled lectins. J Clin Chem Clin Biochem 27:701-702

17. Wu AM, Song SC, Tsai MS, Herp A (2001) A guide to the carbohydrate specificities of applied lectins-2 (updated in 2000). Adv Exper Med Biol 491:551-585

18. Levine MJ, Tabak LA, Reddy MS, Mandel ID (1985) Nature of salivary pellicles in microbial adherence: role of salivary mucins. In: Mergenhagen SE, Rosan B (eds) Molecular basis of oral microbiol adhesion. American Society for Microbiology, Washington, pp 125-130

19. Zehetbauer S, Wojahn T, Hiller KA, Schmalz G, Ruhl S (2009) Resemblance of salivary protein profiles between children with early childhood caries and caries-free controls. Eur J Oral Sci 117:369-373

20. Drews J (2005) Konzentration Lektin-spezifischer Speichelglykane im Verlauf einer experimentellen Gingivits. Zahnmedizinische Dissertation, Zentrum für Zahnmedizin Campus Virchow-Klinikum der Medizinischen Fakultät der Charité, Berlin

21. Aronson M, Medalia O, Schori L, Mirelman D, Sharon N, Ofek I (1979) Prevention of colonization of the urinary tract of mice with Escherichia coli by blocking of bacterial adherence with methyl alpha-D-mannopyranoside. J Infect Dis 139:329-332

22. Steinberg D, Feldman M, Ofek I, Weiss EI (2004) Effect of a high-molecular-weight component of cranberry on constituents of dental biofilm. J Antimicrob Chemother 54:86-89 
23. Weiss EI, Kozlovsky A, Steinberg D, Lev-Dor R, Bar Ness Greenstein R, Feldman M, Sharon N, Ofek I (2004) A high molecular mass cranberry constituent reduces mutans streptococci level in saliva and inhibits in vitro adhesion to hydroxyapatite. FEMS Microbiol Lett 232:89-92

24. Seemann R, Kluck I, Kage A (2006) An in vitro microbial-based model for studying caries-preventive agents. Acta Odontol Scand 64:27-30

25. Gibbons RJ, Qureshi JV (1979) Inhibition of adsorption of Streptococcus mutans strains to saliva-treated hydroxyapatite by galactose and certain amines. Infect Immun 26:1214-1217

26. Nagata K, Shibata S, Inoshita E, Tamagawa H, Shizukuishi E, Tsunemitsu A (1982) The effect of daily mouth rinsing with galactose on dental plaque formation. J Dent Health 32:104107
27. Levine MJ, Herzberg MC, Levine MS, Ellison SA, Stinson MW, Li HC, van Dyke T (1978) Specificity of salivary-bacterial interactions: role of terminal sialic acid residues in the interaction of salivary glycoproteins with Streptococcus sanguis and Streptococcus mutans. Infect Immun 19:107-115

28. Ligtenberg AJ, Veerman EC, de Graaff J, Nieuw Amerongen AV (1990) Saliva-induced aggregation of oral streptococci and the influence of blood group reactive substances. Arch Oral Biol 35:141S-143S

29. Gibbons RJ, Cohen L, Hay DI (1986) Strains of Streptococcus mutans and Streptococcus sobrinus attach to different pellicle receptors. Infect Immun 52:555-561

30. Murray PA, Prakobphol A, Lee T, Hoover CI, Fisher SJ (1992) Adherence of oral streptococci to salivary glycoproteins. Infect Immun 60:31-38 